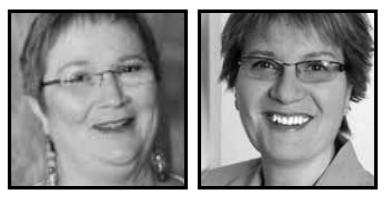

\title{
Developing Interactive Andragogical Online Content for Nursing Students
}

\author{
Denise Passmore and Dianne Morrison-Beedy, \\ University of South Florida
}

\section{ABSTRACT}

There is currently a shortage of registered nurses. This situation is further complicated by increased demands for nurses who are baccalaureate or masters' prepared. Online education can facilitate degree completion for working adults. Nursing faculty, however, are not always adequately prepared to teach online. The purpose of this article is to describe the results of a qualitative research study and thematic analysis of methods utilized by nursing faculty currently involved in teaching online courses. Moreover, the article presents the experiences of nursing faculty who discovered creative methods to develop engaging online content based on relevant clinical experiences, and their transformation from teachers to facilitators of adult learning.

\section{Introduction}

\footnotetext{
1 urses, according to the American Association of Colleges of Nursing (AACN), are the individuals who are most directly responsible for patient care at the most vulnerable points in their lives (American Association of Colleges of Nursing [AACN], 2011). Unfortunately, the current shortage of registered nurses (RNs) throughout the U.S. has placed patient safety at risk. A study of hospitals by Aiken, Clarke, Cheung, Sloane, and Silber (2003) demonstrated that with each new patient added to an RN's workload, chances of patient death after surgery increased by $7 \%$.
} 
One method to help alleviate these current RN shortages has been to concentrate funding on graduating nurses more quickly through two-year, associate degree of science programs offered at vocational and community colleges. However, this solution does not focus on the long term. Procedures and protocols have and continue to evolve mandating that the bedside nurse must also become a much more sophisticated, savvy user of technology in addition to competence in continually updated nursing skills. Consequently, evidence has shown that patient safety and outcomes are compromised when a greater majority of the RN population is not baccalaureate prepared (Aiken et al., 2003; American Association of Colleges of Nursing [AACN], 2011; Maltby \& Andrusyszyn, 1997; Tourangeau et al., 2007; Van den Heede et al., 2009). Thus, national (U.S.-based) organizations, such as the Institute of Medicine (IOM), have called for a more educated nursing workforce to improve patient safety and enhance nursing care (Institute of Medicine, 2010).

This recommendation was based in part on a landmark study by Aiken and colleagues who examined 168 hospitals and found that with every $10 \%$ increase of baccalaureate-prepared nurses, there was a $5 \%$ reduction in patient deaths (Aiken et al., 2003). Aiken and team looked at 133 patient health outcome variables to determine patients' risk of death and even taking all these other variables into account, nurse education level still showed that a greater proportion of nurses with baccalaureate degrees are associated with a decline in patient mortality. This work was corroborated by other researchers both in the U.S. and internationally (Aiken et al., 2011; Maltby \& Andrusyszyn, 1997; McHugh et al., 2013; Tourangeau et al., 2007; Van den Heede et al., 2009). These studies led to the Institute of Medicine report on the future of nursing that recommended that all hospitals be staffed at $80 \%$ by baccalaureate-prepared RNs by 2020 and to encourage all RNs to seek even higher levels of education, thereby increasing the number of graduate-prepared nurses (Institute of Medicine, 2010).

In order to increase access to education, online registered nursing to bachelor (RN-to-BS) as well as graduate nursing programs have been instituted by many colleges and universities, and have resulted in increased student enrollment (Kozlowski, 2004; Ostrow \& DiMaria-Ghalili, 2005). Unlike pre-licensed nursing programs (students who do not have their RN license as yet), these programs consist of very little hands-on training or closely supervised clinical education. Ali, HodsonCarlton, Ryan, Flowers, Rose, and Wayda (2005) state that the phenomenal growth of online education for nurses may help meet the growing need for qualified professional RNs. 
Steiner (2001) reported that in the five years prior to a 2001 study there was a 500\% increase in distance education courses for nursing. Many courses are webbased. Others are delivered through video conferencing, television, audio/video methods, or by faculty members who travel to multiple locations (Steiner, 2001). Teaching online requires an integrated knowledge of content, technology, and pedagogy beyond that expected of faculty members who teach only live classes (Anderson, 2008; Koehler \& Mishra, 2005). Many faculty, however, are unfamiliar with tools and online teaching methods that can be utilized effectively in online education (Hulkari \& Mahlamaki-Kultanen, 2008).

Despite critics' concerns of online educational quality, studies have demonstrated equal if not superior learning in some aspects (Donavant, 2009; McKeown, 2012). For example, online students have been shown to employ broader reading strategies and adapt more easily to instructional strategies that focus on acquisition of lifelong learning skills (Dykman \& Davis, 2008; National Survey of Student Engagement, 2012). Online teaching strategies are key in enabling students to learn how to locate information on their own to foster self-directed learning and continue providing professional skills throughout their careers (Anderson, 2008; Dzubinski, Hentz, Davis, \& Nicolaides, 2012; Hussain, 2013).

Providing quality as well as authentic learning experiences to nursing students is a concern of faculty charged with transitioning nursing programs to a web-based curriculum (Smith, Passmore, \& Faught, 2009). This lack of authenticity and relevance to real-life situations has been frequently cited by nursing students as a reason for withdrawal from online programs (Perry, Boman, Care, Edwards, \& Park, 2008). Teachers of practicing nurses, often with families and jobs, need to look towards methods that engage adult and lifelong learning, and understand the theories and concepts about how adults actually learn.

\section{Andragogical Theory}

Students in RN-to-BS and graduate nursing programs are generally older and more experienced than the typical college-age student (Duff, 1989) and can usually be identified as adults, that is persons mature enough to be held responsible for their own actions (Mezirow \& Associates, 1990). Knowles (1978) says that in regards to learning, we become adults when we accept responsibility for our learning and are self-directed. Therefore, in that $\mathrm{RN}$-to-BS and graduate nursing students can be 
categorized as adult learners, it is important that nursing educators understand adult learners and what it means for them to be online learners (Anderson, 2008; Dzubinski et al., 2012; Hussain, 2013).

One method for accomplishing this objective is to incorporate andragogical theory into the design and development of online courses to increase their effectiveness (Henning, 2012; Williams, 2002). The term andragogy was introduced in 1968 by Malcolm Knowles (Merriam \& Caffarella, 1991), who defined it as "the art and science of helping adults learn" (Knowles, 1978, p. 52) as contrasted with pedagogy which is associated with how children learn. Adult education is cooperative by nature and the teacher's role is more that of facilitator of learning rather than absolute expert. Mezirow and Associates (1990) described adult education as a method for adult learners to foster understanding of the meaning of their experiences, and consequently take action on the resulting insight.

Andragogy is based on six assumptions: 1) adult learners need a reason for learning something; 2) adult learners are self-directed; 3 ) adult learners bring more and different experiences than children to educational experiences; 4) adult learners learn more readily when confronted with real-life situations that require them to attain knowledge in order to cope; 5) adult learners are task-oriented; and 6) adult learners are intrinsically motivated to learn (Knowles, 1989).

These assumptions can provide faculty with a framework for designing and delivering online education. For example, knowing that adults need reasons for learning a particular subject, faculty understand that adult learners are less likely than younger students to participate in activities that are marginal to the course goals such as icebreakers, or activities to foster community without an understanding that these activities provide any direct educational benefits (Anderson, 2008). Andragogical-based courses offer flexibility to learners, and enable some control over their own learning as well as opportunities to apply content to real-life situations (Anderson, 2008; Dzubinski et al., 2012). Additionally, course content and activities should draw to some extent on adult learners' prior experiences, in order for them to contextualize how new information can be integrated into their current knowledge and environment (Anderson, 2008; Arbaugh, 2010; Donavant, 2009; Henderson \& Bradey, 2008). This study examined how nurse educators developed online learning content and integrated activities that addressed adult learning principles. 


\section{Methods}

A phenomenological method was used to explore 16 nursing faculty members' experiences in developing online education. Through one-on-one, open-ended interviews, faculty members were asked to describe how they converted their course material into an online environment. Criteria for inclusion was that nursing faculty: 1) must have taught in an online nursing program for at least one year, 2) began their teaching career in a live venue, and 3) currently taught on a full-time basis in a public university. Adjunct faculty were excluded from this study, since often they do not receive the same type of institutional support and development as full-time faculty (Biro, 2005) and, therefore, may not have similar experiences.

From three to five participants were recruited from four public university colleges of nursing within the same state. One face-to-face interview at the participant's university was scheduled for each individual, and they were provided with a written description of an interview guide prior to the appointment. Each individual was asked to sign a statement of informed consent and verbally affirm his or her consent to be audiotaped. Interviews took approximately one to two hours. Member checking was accomplished through provision of an interview transcription to all participants for the opportunity of removing or clarifying information. Each transcribed interview was examined utilizing Atlas.TI to highlight and track thematic content within the interview and provide a data trail correlating themes with illustrative quotations. Steps for analysis as identified by Moustakas (1994) were incorporated to analyze the data. These analysis steps involved: 1) searching for statements that described the experience, 2 ) grouping statements by meaning and writing a description, 3) describing how the phenomenon was experienced, 4) constructing a description of the meaning for each individual, and 5) constructing an overall meaning of the phenomenon. Institutional review board (IRB) approval was obtained from all participating universities.

\section{Participant Description}

For this study, 16 nursing faculty members from four major state universities were interviewed. All faculty who participated were registered nurses (RNs) and had experience in patient care prior to beginning their teaching careers. Thirteen of the participants had a doctorate degree but all had at least a master's degree in nursing. All taught online in either an RN-to-BS or graduate program. Some also taught 
in traditional face-to-face and clinical courses. In order to preserve anonymity, each of the participants was given a pseudonym; this pseudonym along with the type of degree received, location, and the year each participant graduated from nursing school is included in Table 1 along with length of online teaching experience. The last column in Table 1 describes how each participant reported being prepared to teach online.

\section{Table 1:}

\section{Participant Description}

\begin{tabular}{|c|c|c|c|c|}
\hline UNIVERSITY & PSEUDONYM & $\begin{array}{l}\text { YEAR GRADUATED } \\
\text { FROM NURSING } \\
\text { SCHOOL/ DEGREES }\end{array}$ & \begin{tabular}{|l|} 
\# YEARS \\
TAUGHT \\
ONLINE
\end{tabular} & $\begin{array}{l}\text { TYPE OF PREPARATION TO } \\
\text { TEACH ONLINE }\end{array}$ \\
\hline SU1† & Terry & 1974 / BSN, MSN, MEd & 11 & Mandatory formal training \\
\hline SU1 & Leslie & 1970 / BS, MA, PhD & 5 & Mandatory formal training \\
\hline SU1 & Pat & $\begin{array}{l}1972 \text { / BSN, MEd, } \\
\text { MSN, PhD }\end{array}$ & 7 & $\begin{array}{l}\text { Mentored }{ }^{*} \text {, research project*, } \\
\text { mandatory formal training }\end{array}$ \\
\hline SU1 & Gerry & 1988 / BSN, MSN, PhD & 5 & $\begin{array}{l}\text { Mentored }{ }^{*} \text {, research project*, } \\
\text { mandatory formal training }\end{array}$ \\
\hline SU1 & Jesse & $\begin{array}{l}1970 / \text { BS, MA, MSN, } \\
\text { EdD }\end{array}$ & 2 & Mandatory formal training \\
\hline SU2 & Ronnie & $\begin{array}{l}1967 \text { / Diploma, BSN, } \\
\text { MSN, DSN }\end{array}$ & 5 & Sent to workshops by administration \\
\hline SU2 & Faye & 1973 / BSN, MSN, DSN & 1 & $\begin{array}{l}\text { Reviewed existing courses, } \\
\text { asked peers }\end{array}$ \\
\hline SU2 & Joey & N/A / BSN, MSN, DSN & 8 & Self-taught, workshops \\
\hline SU3 & Casey & N/A / AS, BS, DN & 5 & Self-taught, workshops \\
\hline SU3 & Morgan & 1970 / BSN, MS, PhD & 3 & $\begin{array}{l}\text { Existing course, 1-on-1 training, } \\
\text { workshops }\end{array}$ \\
\hline SU3 & Stacey & 1977 / ASN, BSN, MSN & 1 & $\begin{array}{l}\text { Reviewed existing course, peers, } \\
\text { hybrid classes, workshops }\end{array}$ \\
\hline SU3 & Chris & 1970 / ASN, BSN, MSN & 3 & $\begin{array}{l}\text { Existing course, peers, hybrid classes, } \\
\text { workshops }\end{array}$ \\
\hline SU4 & Ray & 1978 / BSN, MSN, PhD & 6 & $\begin{array}{l}\text { Certificate in Online Teaching, } \\
\text { vendor technical training }\end{array}$ \\
\hline SU4 & Tony & $\begin{array}{l}1976 \text { / AA, BSN, MSN, } \\
\text { PhD }\end{array}$ & 5 & Peers \\
\hline SU4 & Tyler & $\begin{array}{l}1964 \text { / AAS, BHS, } \\
\text { MSN, PhD }\end{array}$ & 4 & $\begin{array}{l}\text { Reviewed existing courses, } \\
\text { vendor technical training }\end{array}$ \\
\hline SU4 & Dale & 1976 / BSN, MSN, PhD & 3 & $\begin{array}{l}\text { Post-graduate certificate in distance } \\
\text { teaching, vendor technical training }\end{array}$ \\
\hline
\end{tabular}

SU=State University $\quad$ * Training received at a previous university 
As shown in Table 1, faculty had various levels of support and experience to prepare them for online teaching. All SU1 faculty members were required to participate in a semester-long mandatory formal education process that requires them to build the first two lessons of their online course under the guidance of an instructional designer. No other universities within the state provide such intensive, formalized training.

At SU2, Ronnie was one of the first nursing faculty to teach online and, consequently, was provided opportunities to attend seminars and workshops to prepare her for this venue. Faye, also from SU2, had no formal or informal training and began teaching by adapting existing courses and relying on peers for informal mentoring. Casey and Joey reported being self-taught as well, though both attended occasional workshops offered by their university to enhance technology and instructional design skills. Morgan began teaching by adapting existing courses but reported that the university provided one-on-one training with the technical support staff as well as instructional design workshops. Stacey and Chris worked offsite at a satellite campus and began their online experience by developing and teaching hybrid classes. Faculty who taught at satellite campuses, such as Stacey and Chris, reported they were often at a disadvantage for workshop attendance due to lengthy drives. All SU4 faculty members receive technical training provided by the learning management system vendor but then relied on colleagues for ongoing mentoring. Both Ray and Dale earned graduate certificates in online teaching from institutions other than their own.

Preparation and training for teaching onlinevaried from mandatorysemesterlong classes to occasional workshops that were optional and frequently difficult to access due to location. Mentoring of new online teachers was also sporadic, and mostly facilitated through an informal network of colleagues willing to assist their peers. The bulk of these training and educational opportunities related to technology or instructional design principles, with little emphasis on educational principles, and theories such as andragogy.

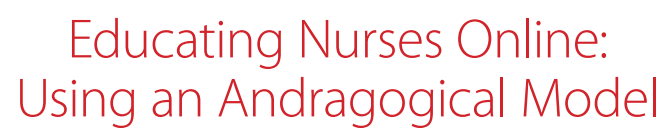

Despite their initial lack of preparation, particularly from a theoretical perspective, most of the faculty genuinely wanted to develop online learning experiences that were authentic, relevant to nursing students, and required critical 
thinking. In order to describe how nursing faculty accomplished these goals, we have analyzed, grouped, and provided a textural description of their statements within the framework of Knowles' assumptions. This section describes how these assumptions were addressed through content, activities, or awareness by the faculty as they reflected on their online course development experiences.

\section{Recognizing That Adults Need a Reason for Learning}

The first assumption of andragogy is that adults need a reason for learning. In this study, we reviewed educators of registered nurses (RNs) who had gone back to school to complete a baccalaureate degree or advanced education at the graduate level. In 2013, there is significant political and economic pressure for RNs to further their education. First, there is the move to employ only baccalaureateprepared nurses in order to comply with the goals of the Institute of Medicine (Institute of Medicine, 2010). Additionally, the need for primary health care providers is greater than ever and advanced registered nurse practitioners (ARNPs) are positioned to fill the void created by a shortage of primary care medical doctors (PR Newswire, 2012). Finding qualified programs for all these students, however, can be problematic. Online education is one way to enable working nurses to return to school for advanced degrees as Dale describes her beliefs regarding this process.

It's not the be all end all but as nurses we really do need to embrace it. We're going to get people into nursing and progress their careers within nurse education or lead them from undergraduate to $R N$ to BSN to graduate even $R N$ to $P h D$. We really do need to embrace these methods I believe. (Dale/3-30-2010)

RNs who return to school understand their reasons for obtaining higher levels of education. However, it is the responsibility of the nursing faculty to provide learning experiences that will meet the students' needs as they progress in their nursing careers.

\section{Adult Learners Are Self-Directed}

In order to enhance the online learning experience, faculty often included activities and assignments that enabled students to pursue their own interests. Ray described that after teaching online for a few semesters, she realized the online class needed more interaction than the lectures and PowerPoint presentations she had recorded from her live classes. Consequently, she redid online content to increase interaction, requiring students to research information relevant to their individual 
educational goals. Gerry, who teaches statistics, required students to apply the principles they learn in class to research articles of their own choosing, and post their conclusions to the discussion board.

If I made them read my articles they were dead. I had lost them. But if I said read your article, at least they're interested in the content and they tended to be a little bit more involved in the discussion and the research. What did that mean for me? A lot of reading and no right answer. No right answer you know, I had 50 students, 50 different articles. There's not a right answer for me to look for in the discussion posting. So I got them involved, expanded their horizons a little bit because they had to read some postings by other topics. (Gerry/4-1-10)

\section{Adult Learners Bring More and Different Experiences}

Many of the faculty in this study described early versions of their online classes as "page-turners" that involved PowerPoint presentations left over from live classes or pages of text uploaded to websites. As they began to feel more comfortable with the online medium, faculty began adding interactive lessons and activities that relied on their adult students' own experiences and knowledge.

Tyler, who taught about cultural differences, wanted to create a group experience that required students to think about different cultures they had encountered as nurses and how these cultures were portrayed in the media. Therefore, she created a group assignment called movie and popcorn.

I gave them a list of movies, but they could go find other ones that clearly depicted cultural, you know cultural phenomenon, and then they would discuss it in their groups... So they have the fun of an experience. (Tyler/4-14-2010)

Other faculty reported relying on student knowledge and experiences, that the faculty themselves may not have. Ray, for example, required that all assignments be submitted to the discussion board to obtain feedback from class peers, relying on their varying nursing practices to provide a broader area of feedback to the student.

The other students are reading it and saying I don't understand what you're trying to say here or what about this or what about that or, where I work... because lots of our students are practicing nurses... it's much more of that kind of peer collegiality sort of interaction. (Ray/4-14-2010) 
Many of the faculty utilized discussion boards which enabled students to share individual expertise with their peers. After finding that whenever she made a post all conversation stopped in order to follow her direction, Tony began appointing class leaders to facilitate the discussions. Faye also relied on student discussion leaders by organizing individuals in discussion groups according to their area of nursing specialization.

And they have more knowledge, like if it's acute care I know basic acute care but I'm not an expert at acute care nursing, but they are already in the acute care setting working there so they can be more supportive than I can with the nitty gritty details about what's going on there. (Faye/4-13-09)

Adult nursing students have experience and knowledge that in some instances may go beyond those of the faculty. Faculty described in this study often relied on these students to share their experiences, and thereby enhance learning for other students. Faculty also attempted to create activities that enabled students to focus on their individual interests and learning goals.

\section{Providing Real-Life Learning Situations and Related Tasks}

Providing actual clinical situations to students in an online venue was challenging to faculty, but also encouraged them to cultivate creative methods that added value to live as well as online classes. Casey, a nurse practitioner as well as faculty, had previously used case studies in classroom situations and consequently, preferring them as a learning strategy, utilized technology to create them for an online venue.

I like to do a lot of case studies. Actual cases. I actually carry a digital camera to clinical with me. I still practice. And over the years I've taken many hundreds of patients not identifying kinds of pictures, and I like to use those and kind of work through cases... in my online when I'm providing them materials, because they can't interact with me. (Casey/4-9-2010)

Additionally, Casey described creating audio files from patients that students could use to learn about heart conditions.

I put these audio files and I make little folders and I'll have actual tapes of the different murmurs, that I've recorded with an electronic stethoscope in clinic over the years. So they'll have the murmur they can hear the murmur and they click 
on another audio file and they hear me talking about the murmur. So they can kind of go back and forth between those. (Casey/4-9-2010)

Ray encouraged students who are studying nursing research to apply the research principles acquired in class to their own work experience when completing class assignments.

We added a project from their clinical sites. We grounded them in ascertaining and thinking about what is the problem in their own clinical settings. We talked about problems, and we learned how to do a review of literature. And then they learned how to critique about 4 or 5 studies, and what is the status of the evidence. Was there enough information to make a clinical change based on what was in the literature? (Ray/4-14-2010)

Terry teaches students about managing health by having them create a plan based on their own personal needs. Working with her IT department she developed a tool that helps students analyze their current fitness needs.

They do their own personal physical plan and hone in on two of their lowest scores based on this survey and they have to set up a personal action plan on how they are going to change. Maybe for instance they have a problem with physical fitness. They have to set up an action plan and then at the end we evaluate it...So it's women and nutrition, each week once again they have a little module to do then they have an assignment, and they have an assessment here for nutrition. They take this assessment and it scores them where they are. They have too much fat, too much whatever in their diet, discuss your score and dietary in your personal action plan. So I tie these personal assessments to their assignment that they will turn in. (Terry/3-30-10)

Field trips were a means of encouraging students to interact with the community, rather than limiting their educational experiences, to sitting in front of a computer. Terry described several field trips she required for a women's health class.

During the contraceptive module they all have to go to a local drug store and they have to bring back information on three different contraceptives sold over the counter. What did they encounter? What did people around them ... how did they feel when they walked in? And they have to bring prices and they discuss this and they have to analyze their experiences. Many of them, this is the first time they ever thought about contraceptives besides condoms; and when 
they see the women's condoms and you know they say I didn't know they were so expensive. So l engage them in field trips. They have two in women's health. They have to go to an agency that has women's services. It can be an abortion clinic, a fertility clinic, an ob/gyn, a health dept, they have to go physically face to face, have an interview, and they have to have it dripping with adjectives. (Terry/3-30-10)

Ronnie, who taught nursing leadership, also assigned student field trips in her course. Students were required to interview nursing managers and compare actual medical staff organizational charts to nursing organizational charts, and draw some conclusions on how the different professions operate within a health care institution.

So that didn't come out of web per se, but I felt the need to do that. More so with web than when I had them... If I had them in a live classroom I could put them in a group, I could observe behaviors, we did games, and I couldn't do that on the web so it forced me to be innovative. I think it was just a different way, not better or worse, it made the web three-dimensional. (Ronnie/4-13-10)

Elliott reported that discussion boards provided a rich supplement to students in community clinical courses. The nursing students, who had been making home health care visits, participated in online discussions regarding their experiences, enabling them to review the differences in value and culture that they encountered.

And it's sort of like a process course. Or what I would call a validation course. You're validating your nursing process from your original education. The discussion boards complement the visits. So when they go in and they do their discussion board it's more information about their home visit. So it's kind of an extension. (Elliott/4-14-10)

These faculty found various methods for ensuring that learning experiences were reflective of real-life situations and engaging to online students. Additionally, assignments were often related to the nursing students' work environment or reallife experiences, increasing the relevancy of the content. For faculty who may not have some of the multimedia resources described here, the Internet provides a vast source of information such as sites that include heart sounds (http://depts.washing ton.edu/physdx/heart/demo.html) or sites like www.MERLOT.org that offer a host of audio/video resources for nursing and other health care fields. 


\section{Facilitating Lifelong Learning}

Ray explained another key element of online education often overlooked by students and faculty. Nursing, like many other professions, requires lifelong learning in order to maintain competencies and knowledge within the field. By engaging in learning on the Internet, students will develop skills to enhance their ability to gather and evaluate relevant information.

The things we can teach a student today in whatever format in this building, when they graduate in six months and get out in practice, you know there's a new IV pump. There's a different medication. Things change so fast in probably any profession that you always have to be learning new things. You need those basics. But that's ongoing learning, and I think that's one thing you can do more so with the online course. Not relying on a textbook. (Ray/4-14-2010)

Primarily because of their mission to encourage lifelong, self-directed learning among their students, many of the faculty participating in this study discovered that online teaching had somewhat changed their role as teacher and they often found themselves as facilitators of learning. Elliott talks about the struggle to discern when to facilitate versus when to teach.

Facilitation versus the teaching moment is a biggie. I think you need to learn how to really hear for what they're asking you. Probably no different than listening orally when people are talking to you what are they really saying, rather than just reacting. But I need to be very thoughtful in my responses to students. So if I was telling somebody new that's what I think I would try to help them to see. You don't just react to everything, give an answer. (Elliott/4-14-09)

Another participant, Dale, described the transformation process that she experienced as an online teacher.

Which is, you do not see yourself as the sage on the stage. You are a facilitator of active learning. So when you see it that way, you see that the students have that much more responsibility in their learning and you must create that environment, and that community of learners. (Dale/3-30-2010)

Leslie discussed how she tries to emphasize that students are in charge of their learning, particularly the graduate students. She describes herself as a facilitator and explains to her students that she is there to help them learn, but they are professionals and ultimately responsible for their own learning. Pat also described herself as 
a resource to students and a facilitator of learning in her research course. She believes that students in her online class fared better than live classroom students because they had to search for their own answers. She indicated that live classroom students listened to lectures but often failed to read assignments, whereas online students were better prepared to study research on their own due to the self-directed nature of online learning. Because of the differences necessitated in online teaching, Morgan revealed that her method of teaching all types of classes has irrevocably changed.

It's changed my whole way that I think and approach students in the classroom. Completely changed. Because I virtually forced myself at first, say you're going to design this face-to-face course and you're not going to lecture. You're not going to lecture anymore. So how are you going to do it? I think the distance learning has changed the way I teach face to face. I think it's had a big difference. (Morgan/3-30-10)

These faculty revealed that they had reconsidered the evolution of their role as traditional faculty to facilitators of learning. This was in part due to the need to foster self-directed, lifelong learning habits in their students. Faculty assured students of their availability as guide and resource but emphasized students' need to take control of their own learning.

\section{Discussion and Implications}

Online education offers an alternative to traditional face-to-face programs for nursing students who are unable to attend live classes due to geographical challenges, or employment and family demands. This study described how nursing faculty who transitioned from live to online teaching found ways to create interactive, engaging content that addressed the adult learning needs of their students, including relevance and application of prior knowledge. Activities made use of technology, such as digital photos and audio, documenting health conditions in actual patients, or relied on low-tech solutions such as "field trips" that placed students in the community. Even more significant was the emphasis faculty placed on providing learning experiences and skills that would facilitate lifelong learning competencies, which are vital for nursing career progression.

Developing interactive content appropriate to online adult learners requires that faculty understand not only the functionality and capability of the technology 
at their disposal, but that they also understand andragogical learning principles in order to ensure engagement of their online adult students as well as provide quality learning experiences. Faculty, as well as students, often do not think of themselves as being involved in adult education, and both can easily adopt behaviors with which they are more familiar, such as pedagogical approaches or dependence on faculty to control the learning experience (Dzubinski et al., 2012).

Faculty must make a paradigm shift when they move to online teaching (Henning, 2012). In this study, most of the participants came to realize that traditional methods of teaching (i.e., lecturing, "sage on the stage") should be supplemented, or even replaced, with participatory learning strategies that give at least some control of learning to their adult students. Significantly, several faculty reported adopting andragogical methods within their traditional live classrooms, acknowledging not only the significance of student life experiences but also the importance of fostering lifelong learning among their students.

The participants in this study all taught in large, public universities and were given the opportunity to develop their own course content rather than reliance on publisher- or university-mandated curriculum. However, most faculty are not introduced to andragogical theory prior to teaching online; instead they are often rushed through technology orientations that attempt to prepare them on how to use the technology without understanding the principles that guide its use in developing adult-oriented content (Johnson, Wisniewski, Kuhlemeyer, Isaacs, \& Krzykowski, 2012). If online nursing programs are to successfully prepare the workforce of the future, they must ensure that faculty are prepared technically as well as theoretically and given opportunities to develop content that is relevant to adult nursing students. Successful online nursing programs require a well-thought-out infrastructure in order to meet both student and faculty needs (Cornelius \& Glasgow, 2007). The faculty whose experiences were documented in this article were mostly enthusiastic about the opportunity to develop these activities. Recommendations to facilitate collaboration of ideas among nursing faculty include peer-to-peer mentoring programs that would enable faculty, who have developed methods for effectively teaching online, to share their experiences with faculty new to this environment. Collaboration could be done efficiently through listservs or informal workshops, live or online, where faculty present and discuss methods they have utilized, thereby developing a community of practice (Reilly, Vandenhouten, Gallagher-Lepak, \& RalstonBerg, 2012). Finding a way to share effective and innovative online teaching methods among nursing faculty could provide a means of aiding faculty in the development of online courses, and should be a priority amongst educators of one of our most treasured and increasingly scarce resources, nurses. 


\section{References}

Aiken, L. H., Cimiotti, J. P., Sloane, D. M., Smith, H. L., Flynn, L., \& Neff, D. F. (2011). Effects of nurse staffing and nurse education on patient deaths in hospitals with different nurse work environments. Medical Care, 49(12), 1047-1053. doi: 10.1097/ MLR.0b013e3182330b6e

Aiken, L. H., Clarke, S. P., Cheung, R. B., Sloane, D. M., \& Silber, J. H. (2003). Educational levels of hospital nurses and surgical patient mortality. Jama, 290(12), 1617-1623.

Ali, N. S., Hodson-Carlton, K., Ryan, M., Flowers, J., Rose, M., \& Wayda, V. (2005). Online education: Needs assessment for faculty development. Journal of Continuing Education in Nursing, 36(1), 32-38.

American Association of Colleges of Nursing (AACN). (2011). Creating a more highly qualified nursing workforce, 2012. Retrieved from http://www.aacn. nche.edu/media-relations/fact-sheets/ nursing-workforce

Anderson, T. (Ed.). (2008). The Theory and Practice of Online Learning [electronic resource] (2nd ed.): Edmonton: Athabasca University Press, 2008.

Arbaugh, J. B. (2010). Sage, guide, both, or even more? An examination of instructor activity in online MBA courses. Computers \& Education, 55(3), 1234-1244.

Biro, S. C. (2005). Adjunct faculty perceptions about their preparation, support, and value as online instructors. Ed.D. doctoral dissertation, Widener University, PA, United States. Retrieved from http://proquest. umi.com/pqdweb?did=1317311891\&Fmt $=7 \&$ clientld $=65345 \& \mathrm{RQT}=309 \& \mathrm{VName}=$ PQD

Cornelius, F., \& Glasgow, M. E. S. (2007). The development and infrastructure needs required for success--One college's model: Online nursing education at Drexel University. TechTrends: Linking Research and Practice to Improve Learning, 51(6), 32-35.

Donavant, B. W. (2009). The new, modern practice of adult education: Online instruction in a continuing professional education setting. Adult Education Quarterly: A Journal of Research and Theory, 59(3), 227-245.

Duff, V. (1989). Perspective transformation: the challenge for the RN in the baccalaureate program. Journal of Nursing Education, 28(1), 38-39.

Dykman, C. A., \& Davis, C. K. (2008). Online education forum: Part one - The shift toward online education. Journal of Information Systems Education, 19(1).

Dzubinski, L., Hentz, B., Davis, K. L., \& Nicolaides, A. (2012). Envisioning an adult learning graduate program for the early 21 st century: A developmental action inquiry study. Adult Learning, 23(3), 103-110.

Henderson, M., \& Bradey, S. (2008). Shaping online teaching practices: The influence of professional and academic identities. Campus-Wide Information Systems, 25(2), 85-92.

Henning, T. B. (2012). Writing professor as adult learner: An autoethnography of online professional development. Journal of Asynchronous Learning Networks, 16(2), 9-26.

Hulkari, K., \& Mahlamaki-Kultanen, S. (2008). Reflection through web discussions: Assessing nursing students' work-based learning. Journal of Workplace Learning, 20(3), 157-164.

Hussain, I. (2013). A study of learners' reflection on andragogical skills of distance education tutors. Online Submission.

Institute of Medicine. (2010). The future of nursing: Leading change, advancing health. Washington, D.C.

Johnson, T., Wisniewski, M. A., Kuhlemeyer, G., Isaacs, G., \& Krzykowski, J. (2012). Technology adoption in higher education: Overcoming anxiety through faculty bootcamp. Journal of Asynchronous Learning Networks, 16(2), 63-72.

Knowles, M. S. (1978). The adult learner: a neglected species. Houston, TX: Gulf.

Knowles, M. S. (1989). The making of an adult educator: An autobiographical journey (First ed.). San Francisco: Jossey-Bass. 
Koehler, M. J., \& Mishra, P. (2005). What happens when teachers design educational technology? The development of technological pedagogical content knowledge. Journal of Educational Computing Research, 32(2), 131-152.

Kozlowski, D. (2004). Factors for consideration in the development and implementation of an online RN-BSN course. Faculty and student perceptions. CIN: Computers, Informatics, Nursing, 22(1), 34-43.

Maltby, H. J., \& Andrusyszyn, M. A. (1997). Perspective transformation: challenging the resocialization concept of degree-seeking registered nurses. Nurse Educator, 22(2), 9-11.

McHugh, M. D., Kelly, L. A., Smith, H. L., Wu, E. S., Vanak, J. M., \& Aiken, L. H. (2013). Lower mortality in magnet hospitals. Med Care, 51(5), 382-388. doi: 10.1097/ MLR.0b013e3182726cc5

McKeown, K. D. (2012). Can Online Learning Reproduce the Full College Experience? Center for Policy Innovation Discussion Paper. Number 3: Heritage Foundation.

Merriam, S. B., \& Caffarella, R. S. (1991). Learning in adulthood: a comprehensive guide. San Francisco: Jossey-Bass.

Mezirow, J., \& Associates. (1990). Fostering critical reflection in adulthood: a guide to transformative and emancipatory learning. San Francisco: Jossey-Bass.

Moustakas, C. (1994). Phenomenological research methods. Thousand Oaks, CA: SAGE.

National Survey of Student Engagement. (2012). Fostering Student Engagement Campuswide: Annual Results 2011. Retrieved from http://nsse.iub.edu/NSSE_2011_Results/ pdf/NSSE_2011_AnnualResults.pdf

Ostrow, L., \& DiMaria-Ghalili, R. (2005). Distance education for graduate nursing: one state school's experience. Journal of Nursing Education, 44(1), 5-10.
Perry, B., Boman, J., Care, W. D., Edwards, M., \& Park, C. (2008). Why do students withdraw from online graduate nursing and health studies education? Journal of Educators Online, 5(1).

PR Newswire. (2012). Nurse Practitioners Provide Solutions to Shortage of Primary Health Care Providers Retrieved from http://www.prnewswire.com/

Reilly, J. R., Vandenhouten, C., Gallagher-Lepak, S., \& Ralston-Berg, P. (2012). Faculty development for e-learning: A multi-campus community of practice (COP) approach. Journal of Asynchronous Learning Networks, 16(2), 99-110.

Smith, G. G., Passmore, D., \& Faught, T. (2009). The challenges of online nursing education. Internet and Higher Education, 12(2), 98-103.

Steiner, S. D. H. (2001). The use of asynchronous online learning in family nurse practitioner programs: A descriptive study. Ph.D. doctoral dissertation, University of Wyoming, United States -- Wyoming. Retrieved from http://proquest.umi.com/pqdweb?did=7 28969991\&Fmt=7\&clientld =65345\&RQT $=$ 309\&VName $=P Q D$

Tourangeau, A. E., Doran, D. M., Hall, L. M., Pallas, L. O. B., Pringle, D., Tu, J. V. et al. (2007). Impact of hospital nursing care on 30-day mortality for acute medical patients. Journal of Advanced Nursing, 57(1), 32-44.

Van den Heede, K., Lesaffre, E., Diya, L., Vleugels, A., Clarkse, S.P., Aiken, L.H. et al. (2009). The relationship between inpatient cardiac surgery mortality and nurse numbers and educational level: Analysis of administrative data. International Journal of Nursing Studies, 46, 796-803.

Williams, T. (2002). Transformative Learning, Adult Learners and the September 11 Terrorism Incidents in North America. 


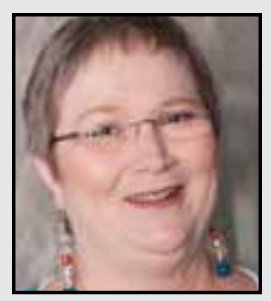

Denise Passmore $(\mathrm{PhD})$ is Assistant Professor at the University of South Florida-College of Nursing. With both a master's and doctorate in adult education, Dr. Passmore has focused on developing and delivering online education in corporate and nursing education for the last 15 years. She has participated in research that involved presenting online educational options for nursing faculty, African-American men struggling with prostate cancer, and individuals suffering with chemo-induced neuropathy.

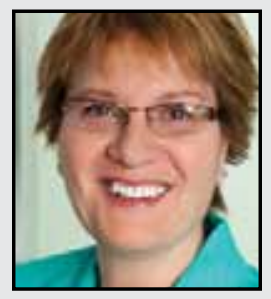

Dianne Morrison-Beedy (PhD) is Dean of the College of Nursing, Senior Associate Vice President of USF Health at the University of South Florida, professor of Nursing and Public Health, and Visiting Professor in the Faculty of Nursing, Burapha University (Thailand). Dr. Morrison-Beedy has taught nursing for over 25 years and has an extensive body of research that focuses on HIV/AIDS risk reduction, especially for vulnerable adolescent girls. She has been nationally recognized for the college's veterans and returning military research and education initiatives.

LINK TO:

http://health.usf.edu/nursing/index.htm 